\title{
Supplementary material to manuscript: Humans and the Missing C-Sink: Erosion and burial of soil carbon through time
}

Thomas Hoffmann ${ }^{1 *}$, Simon M. Mudd ${ }^{2}$, Kristof van Oost ${ }^{3}$, Gert Verstraeten ${ }^{4}$, Gilles Erkens ${ }^{5}$, Andreas Lang ${ }^{6}$, Hans Middelkoop ${ }^{5}$, John Boyle ${ }^{6}$, Jed Kaplan ${ }^{7}$, Jane Willenbring ${ }^{8}$, Rolf Aalto ${ }^{9}$

1 Department of Geography, University Bonn, Meckenheimer Allee 166, 53115 Bonn, Germany

2 School of Geosciences, University of Edinburgh, Drummond Street, Edinburgh EH8 9XP, UK

3 Earth and Life Institute, Université catholique de Louvain, Bâtiment Mercator, Place L. Pasteur 3, B-1348 Louvain-la-Neuve, Belgium

4 Department of Earth and Environmental Sciences, University of Leuven, Celestijnenlaan 200e, 3001 Heverlee, Belgium

5 Department of Physical Geography, University of Utrecht, Heidelberglaan 2, 3584 CS Utrecht, The Netherlands

6 School of Environmental Sciences, University of Liverpool, Liverpool L69 3GP, UK

7 Institute of Environmental Engineering, Ecole Polytechnique Fédérale de Lausanne, Station 2, 1015 Lausanne, Switzerland

8 University of Pennsylvania, Department of Earth and Environmental Science, 240 S. 33rd Street, Philadelphia, PA 19104-6313, USA

${ }^{9}$ College of Life and Environmental Sciences, University of Exeter, Rennes Drive, Exeter EX4 4RJ, UK

*Correspondence and requests for materials should be addressed to Thomas.Hoffmann@unibonn.de

\section{Methods and data for the Figure 2}

Lakes and impoundments: Lake data are from Finland (Pahunen, 2000), and impoundment data from Iowa (Downing et al., 2008). Both have their C sink life expectancy calculated as water depth divided by the sediment accumulation rate. The $\mathrm{C}$ accumulation rates are normalised to catchment area. Unpublished data (John Boyle) from other parts of the world show other lakes and impoundments to plot in a broad field extending between and overlapping with these two large published data sets, and suggest that these are a good approximation of the global situation.

Floodplain deposit: Floodplain data are $115{ }^{14} \mathrm{C}$-samples from overbank deposits within the German part of the Rhine basin (for more information on the spatial distribution see Hoffmann et al., 2009; Hoffmann et al., 2008). The complied inventory includes the calibrated ${ }^{14} \mathrm{C}$-age and the sample depth. Sample depth [mm] was divided by age to calculate the average sedimentation rate $\left[\mathrm{mm} \mathrm{a}^{-1}\right]$ for each ${ }^{14} \mathrm{C}$-samples. 
The life expectancy is based on accommodation space divided by the calculated sedimentation rate. Accommodation space is approximated by the maximum thickness of overbank deposits (i.e. $5 \mathrm{~m}$ derived from maximum sample depth in the ${ }^{14} \mathrm{C}$-inventory), which results from the balance between overbank deposition and channel migration. The applied model therefore assumes that sedimentation rates are constant and do not change with increasing deposition. Since sedimentation rates decrease with increasing sample age calculated life expectancies represent minimum ages.

Carbon accumulation rate for each sample was given by the sample depth multiplied with the average bulk density of $1500 \mathrm{~kg} \mathrm{~m}^{-3}$ and an average soil organic carbon concentration of floodplain deposits of $1.11 \%$ (see also methods and data for Figure 3).

Peat bog: Data are from (Clymo, 1984), (Yu et al., 2003), (Belyea and Malmer, 2004), and (Yu, 2011). The rates are present day sink rate, and the life expectancy of the sink is the expected time in years until the sink rate falls to $10 \%$ of its present day value based on quoted fitting parameters for the decay models of (Yu et al., 2003) and (Clymo, 1984). The OC flux data for (Clymo, 1984) assumes that OC comprises $50 \%$ of the dry peat mass. The low number of sites included in the diagram reflects the scarcity of studies that quantify long-term peat decay. Tight clustering of included sites leads us to conclude that the plotted field is a reasonable first approximation for a globally representative sample.

Forest: Data are from (Fahey et al., 2005), (Goodale et al., 2002) and (Keeton et al., 2011). The C sink rate is taken as the initial value following establishment of the forest. The life expectancy of the $\mathrm{C}$ sink is the expected time in years until the sink rate falls to $10 \%$ of its initial value based on fitting a saturation exponential representation of the (Bormann and Likens, 1979) conceptual model (by which an asymptote is reached within 300 years). As for the peat data we include only a small number of well-constrained sites. Again, tight clustering leads us to assume this provide a reasonable first approximation of the global situation.

\section{Methods and data for Figure 3}

Holocene sediment and carbon burial on hillslopes and in floodplains as shown in Figure 3 are derived from a compilation of published sediment budgets on Central European regions that were affected by human induced soil erosion during the last 7500 years. A detailed description of the inventory is given by Hoffmann et al. (2013). The inventory (as summarized in Tab. S1 in Hoffmann et al., 2013) contains estimates on 41 hillslope and 36 floodplain storages of fine sediments $(<2 \mathrm{~mm})$.

Generally, sediment storage in Central Europe is inferred from a large number of auger holes and boreholes evenly spaced on hillslopes and floodplains to estimate the thickness of sediments associated with human induced soil erosion. Information on sediment thickness on hillslopes is extrapolated to sediment volumes for larger areas based on relationships of sediment thickness and topographic parameters. Floodplain storage is generally quantified by multiplying the extent of floodplains along selected channel reaches with representative thicknesses of overbank fines. Hillslope and floodplain storage is related to fine sediments resulting from agricultural soil erosion after the onset of Neolithic agriculture some 7500 years ago. To correct for climate induced, pre-Neolithic floodplain storage it was assumed that the majority $(\sim 85 \%)$ of total storage volumes relates to human impacts. 
A power law scaling of sediment storage and basins size was used to extrapolate the hillslope and floodplain storage to the non-alpine part of the Rhine basins with a basin size of $185.000 \mathrm{~km}^{2}$. The uncertainty of the extrapolation was evaluated using a bootstrap approach of the power law scaling.

Carbon storage was estimated using an inventory of published measurements of OC concentration from Holocene hillslope $(n=366)$ and floodplain $(n=1126)$ deposits. In the absence on any correlation of $\mathrm{OC}$ concentration with large scale topographic and lithological indices, the average $\mathrm{OC}$ concentrations for hillslope and floodplain deposits were multiplied with the sediment mass to calculate total OC. Owing to the simplicity of this approach, we cannot exclude that a certain fraction of the OC stored in hillopes and floodplain deposits is derived from in situ soil formation. Therefore, we argue that the calculated OC storage is not fully associated with lateral sediment fluxes caused by human induced soil erosion. However, in the case of floodplain sedimentation, high sequestration rates are only maintained as long as floodplain sedimentation continues (see chapter 4), and are thus conditioned by high sedimentation rates and consequently linked to human induced soil erosion.

For more details on the methods, results and limitations the reader is referred to read the original study of Hoffmann et al. (2013).

\section{References}

Belyea, L. R., and Malmer, N.: Carbon sequestration in peatland: Patterns and mechanisms of response to climate change, Global Change Biology, 10, 1043-1052, 2004.

Bormann, F. H., and Likens, G. E.: Pattern and process in a forested ecosystem, Springer Verlag, New York, 253 pp., 1979.

Clymo, R. S.: The limits to peat bog growth, Philosphical Transactions of the Royal Society B, 303, 605-654, 1984.

Downing, J. A., Cole, J. J., Middelburg, J. J., Striegl, R. G., Duarte, C. M., Kortelainen, P., Prairie, Y. T., and Laube, K. A.: Sediment organic carbon burial in agriculturally eutrophic impoundments over the last century, Global Biogeochemical Cycles, 22, Gb1018, doi: 10.1029/2006gb002854, 2008.

Fahey, T. J., Siccama, T. G., Driscoll, C. T., Likens, G. E., Campbell, J., Johnson, C. E., Battles, J. J., Aber, J. D., Cole, J. J., Fisk, M. C., Groffman, P. M., Hamburg, S. P., Holmes, R. T., Schwarz, P. A., and Yanai, R. D.: The biogeochemistry of carbon at Hubbard Brook, Biogeochemistry, 75, 109-176, 2005.

Goodale, C. L., Apps, M. J., Birdsey, R. A., Field, C. B., Heath, L. S., Houghton, R. A., Jenkins, J. C., Kohlmaier, G. H., Kurz, W., Liu, S. R., Nabuurs, G. J., Nilsson, S., and Shvidenko, A. Z.: Forest carbon sinks in the northern hemisphere, Ecological Application, 12, 891-899, 2002.

Hoffmann, T., Lang, A., and Dikau, R.: Holocene river activity: analysing 14C-dated fluvial and colluvial sediments from Germany, Quaternary Science Reviews, 27, 2031-2040, 2008.

Hoffmann, T., Erkens, G., Gerlach, R., Klostermann, J., and Lang, A.: Trends and controls of Holocene floodplain sedimentation in the Rhine catchment, Catena 77, 96-106, 2009.

Hoffmann, T., Schlummer, M., Verstraeten, G., and Notebaert, B.: Significance of sediment and carbon storage on hillslopes and floodplains, Global Biogeochemical Cycles, 27, doi:10.1002/gbc.20071, 22013, 2013. 
Keeton, W. S., Whitman, A. A., McGee, G. C., and Goodale, C. L.: Late-successional biomass development in northern hardwood-conifer forests of the northeastern united states, Forest Science, 57, 489-505, 2011.

Pahunen, H.: Carbon in finnish lake sediments, Geological Survey of Finland, Special Paper 29, 2000.

Yu, Z. C., Vitt, D. H., Campbell, I. D., and Apps, M. J.: Understanding holocene peat accumulation pattern of continental fens in western canada, Canadian Journal of Botany, 81, 267-282, 2003.

Yu, Z. C.: Holocene carbon flux histories of the world's peatlands: Global carbon-cycle implications, Holocene, 21, 761-774, 2011. 